\section{CardioRenal Medicine}

\title{
Prevalence of Subclinical Hypothyroidism in Patients with End-Stage Renal Disease and the Role of Serum Albumin: A Cross-Sectional Study from South India
}

\author{
Ghanshyam Palamaner Subash Shantha ${ }^{\mathrm{a}} \quad$ Anita Ashok Kumar ${ }^{\mathrm{a}}$ \\ Viraj Bhise $^{a}$ Rohit Khanna ${ }^{b}$ Kamesh Sivagnanam ${ }^{a}$ \\ Kuyilan Karai Subramanian ${ }^{a}$

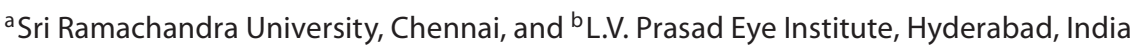

\section{Key Words}

Albumin $\cdot$ Chronic kidney disease $\cdot$ Serum albumin $\cdot$ Subclinical hypothyroidism

\begin{abstract} associated with $\mathrm{SCH}$ in our study.

Background/Aim: Subclinical hypothyroidism (SCH) and end-stage renal disease (ESRD) are independent risk factors for cardiovascular mortality. We aimed to study the prevalence of SCH in ESRD patients and assessed its associated risk factors. Methods: This cross-sectional study was conducted at 2 tertiary-care centers in Chennai, India, over a 3-year period. The study group comprised 137 patients with ESRD on thrice weekly regular maintenance hemodialysis. Free thyroxine $\left(\mathrm{FT}_{4}\right)$ and thyroid-stimulating hormone (TSH) were measured using an electrochemiluminescence immunoassay. SCH was defined as TSH ranging between 4.5 and $10 \mathrm{mIU} / \mathrm{l}$ with normal $\mathrm{FT}_{4}(0.93-1.7 \mathrm{ng} / \mathrm{dl})$. Patients with overt hypothyroidism, $\mathrm{SCH}$ and overt hyperthyroidism, those on medications affecting thyroid function and pregnant women were excluded from the study. Results: Of 137 ESRD patients (mean age: $43 \pm 13.38$ years), 107 were males $(78.1 \%)$, 45 diabetics (32.8\%), 127 hypertensives (92.7\%), and 38 smokers (27.7\%). Prevalence of SCH was $24.8 \%$. In unadjusted (OR: 3.37, 95\% Cl: 1.91-5.21) and adjusted (for age, gender, $\mathrm{HbA}_{1 \mathrm{C}}$, and albumin/creatinine ratio; OR: $3.11,95 \% \mathrm{Cl}: 2.15-4.98)$ logistic regression analysis, serum albumin was significantly associated with $\mathrm{SCH}$. Further, multiple linear regression identified that for every $1 \mathrm{~g} / \mathrm{dl}$ drop in serum albumin TSH increased by $4.61 \mathrm{mlU} / \mathrm{l}$ (95\% Cl: 2.75-5.92). Conclusion: We observed a high prevalence of SCH in our ESRD patients. Also, serum albumin was significantly 


\section{CardioRenal Medicine}

Cardiorenal Med 2011;1:255-260

\begin{tabular}{l|l}
\hline DOI: 10.1159/000332757 & (c) 2011 S. Karger AG, Basel
\end{tabular}

Published online: October 12, 2011

www.karger.com/crm

Shantha et al.: Hypothyroidism and CKD

\section{Introduction}

The estimated prevalence rates of chronic kidney disease (CKD) and end-stage renal disease (ESRD) in India are 800 and 200 per million inhabitants, respectively [1]. In South India, the main causes of CKD in decreasing order of prevalence are diabetic nephropathy (29.6\%), chronic interstitial nephritis (20.4\%), chronic glomerulonephritis (17.4\%), and hypertensive nephropathy (11\%) [2]. Studies have clearly demonstrated an association between CKD and increased cardiovascular mortality. Ryan et al. [3] reported an increase in the risk of cardiovascular mortality with decreasing glomerular filtration rate (GFR), with a marked increase when the estimated GFR was $<45 \mathrm{ml} / \mathrm{min} / 1.73 \mathrm{~m}^{2}$.

Subclinical hypothyroidism ( $\mathrm{SCH})$ is diagnosed when the serum thyroid-stimulating hormone (TSH) level is high (range: $4.2-10 \mu \mathrm{IU} / \mathrm{ml}$ ) but the corresponding serum-free thyroxine $\left(\mathrm{FT}_{4}\right)$ level is within normal limits (range: $0.93-1.7 \mathrm{ng} / \mathrm{dl}$ ). A recent review has observed that $\mathrm{SCH}$ was prevalent in $4-8 \%$ of the general population in western countries, and in women who were $>60$ years of age it was prevalent in up to $15-18 \%$ [4]. SCH is recognized as a risk factor for atherosclerotic cardiovascular disease (CVD), hyperlipidemia, low-grade inflammation and hypercoagulability [5-7]. As ESRD and SCH are independent risk factors for CVD mortality, it is possible that patients suffering from both disease entities may have a higher CVD risk.

Previous studies have consistently shown an increased prevalence of SCH in CKD patients compared to normal controls [8-11]. There is a paucity of Indian data with respect to $\mathrm{SCH}$ prevalence in patients with ESRD. Also, factors associated with SCH in ESRD have not yet been clearly defined. Hence, this study is our effort to identify the prevalence of SCH in ESRD patients from South India and its associated risk factors.

\section{Patients and Methods}

This was a cross-sectional study conducted at 2 tertiary-care centers in South India. The study was conducted over a 3-year period (August 2007 to July 2010). Patients with overt hypothyroidism, SCH and overt hyperthyroidism, those on medications affecting thyroid function, e.g. lithium and high-dose steroids (hydrocortisone $>100 \mathrm{mg}$ or equivalent dose of other commonly used steroids), and pregnant women were excluded from the study. Hence, from a total of 176 patients ( 91 from center 1 and 85 from center 2) who underwent hemodialysis during this period, 39 patients with the above-mentioned features were excluded. Consequently, the remaining 137 consecutive patients with ESRD (70 from center 1 and 67 from center 2) receiving thrice weekly maintenance hemodialysis formed the study cohort. Demographic characteristics (age, gender, diabetes mellitus, current smoking, and duration of dialysis), laboratory variables [hemoglobin, blood urea nitrogen, serum levels of creatinine, albumin, phosphorus, and calcium, alkaline phosphatase, a single determination of the albumin/creatinine ratio (ACR) in a spot urine sample, and fasting lipid profile], clinical parameters (systolic and diastolic blood pressure, and body mass index) were obtained from all study participants. Thyroid functions were evaluated for all patients. TSH was measured using Roche Elecsys modular analytics E 170 with electrochemiluminescence immunoassay (ECLIA method). The analytical sensitivity of TSH is $0.005 \mu \mathrm{IU} / \mathrm{ml}$ and of $\mathrm{FT}_{4}$ it is $0.023 \mathrm{ng} / \mathrm{dl}$. High serum TSH (>4.5 $\mu \mathrm{IU} / \mathrm{ml}$; normal range: $0.27-4.5 \mu \mathrm{IU} / \mathrm{m}$ ) and normal $\mathrm{FT}_{4}$ levels (normal range: $0.93-1.7 \mathrm{ng} / \mathrm{dl}$ ) were required for the diagnosis of $\mathrm{SCH}$. Patients with high TSH $(>4.5 \mu \mathrm{IU} / \mathrm{ml})$ and low $\mathrm{FT}_{4}$ levels $(<0.93 \mathrm{ng} /$ dl) were classified as being overt hypothyroid irrespective of whether they had symptoms of hypothyroidism or not. Informed consent was obtained from all the study participants, and the ethics committees of both tertiary-care hospitals approved the study.

Statistical Analysis

Baseline characteristics of the study participants were expressed as means \pm SD and percentages. Prevalence of SCH was also determined (n/\%). Comparisons between both groups, namely patients with $\mathrm{SCH}$ and patients with normal TSH, were done using Student's t test (for continuous variables) and the $\chi^{2}$ 


\section{CardioRenal Medicine}

Table 1. Baseline characteristics of the study participants

\begin{tabular}{lccc}
\hline Patient characteristics & $\begin{array}{c}\text { All participants } \\
(\mathrm{n}=137)\end{array}$ & $\begin{array}{c}\text { Patients with SCH } \\
(\mathrm{n}=34)\end{array}$ & $\begin{array}{c}\text { Patients with normal } \\
\text { TSH }(\mathrm{n}=103)\end{array}$ \\
\hline Age, years & $43 \pm 13.3$ & $39 \pm 9.3$ & $41 \pm 11.2$ \\
Males, $\mathrm{n}$ (\%) & $107(78.1 \%)$ & $25(73.5 \%)$ & $82(79.6 \%)$ \\
Diabetics, $\mathrm{n}$ (\%) & $45(32.8 \%)$ & $17(50.0 \%)$ & $28(27.2 \%)$ \\
Smokers, $\mathrm{n}$ (\%) & $38(27.7 \%)$ & $14(41.2 \%)$ & $24(23.3 \%)$ \\
Duration of dialysis, years & $5.6 \pm 2.2$ & $5.5 \pm 2.1$ & $5.6 \pm 2.5$ \\
Hemoglobin, g/dl & $8.5 \pm 1.5$ & $9.1 \pm 0.8$ & $8.5 \pm 1.0$ \\
Body mass index & $21.5 \pm 3.4$ & $22.1 \pm 3.1$ & $22.7 \pm 2.9$ \\
Systolic blood pressure, mm Hg & $142 \pm 10.7$ & $139 \pm 12.5$ & $141 \pm 11.9$ \\
Diastolic blood pressure, mm Hg & $86.3 \pm 9.2$ & $84.9 \pm 11.2$ & $87.3 \pm 8.7$ \\
Blood urea nitrogen, mg/dl & $119.8 \pm 67.1$ & $91.0 \pm 40.2$ & $121.0 \pm 32.9$ \\
Creatinine, mg/dl & $9.0 \pm 4.0$ & $9.2 \pm 3.0$ & $10.0 \pm 1.9$ \\
Serum calcium, mg/dl & $8.4 \pm 1.4$ & $8.5 \pm 1.2$ & $8.9 \pm 1.1$ \\
Serum phosphate, mg/dl & $5.5 \pm 1.8$ & $5.2 \pm 1.4$ & $5.4 \pm 1.3$ \\
Serum albumin, g/dl & $3.7 \pm 0.5$ & $2.5 \pm 0.8 *$ & $3.8 \pm 0.4$ \\
Alkaline phosphatase, IU & $162.4 \pm 147.9$ & $161.0 \pm 103.5$ & $174.0 \pm 78.9$ \\
FT, ng/dl & $1.2 \pm 0.2$ & $1.1 \pm 0.2$ & $1.2 \pm 0.2$ \\
TSH, $\mu$ IU/ml & $4.2 \pm 2.5$ & $5.1 \pm 3.1$ & $3.2 \pm 0.6$ \\
HbA \% $\%$ & $8.7 \pm 0.7$ & $8.9 \pm 0.5$ & $9.1 \pm 0.3$ \\
ACR, mg/g & $1,573.6 \pm 523.1$ & $1,476.0 \pm 356.5$ & $1,640.1 \pm 580.8$ \\
Total cholesterol, mg/dl & $193.4 \pm 31.2$ & $193 \pm 36.5$ & $192.7 \pm 35.2$ \\
HDL cholesterol, mg/dl & $46.5 \pm 5.76$ & $44.2 \pm 7.9$ & $47.2 \pm 8.3$ \\
LDL cholesterol, mg/dl & $116.3 \pm 33.9$ & $115 \pm 37.4$ & $114.8 \pm 33.8$ \\
Triglycerides, mg/dl & $130.6 \pm 67.2$ & $128.9 \pm 72.8$ & $130 \pm 68.3$ \\
\hline & & &
\end{tabular}

${ }^{*} \mathrm{p}=0.012$. All other comparisons were nonsignificant. All values are mean levels measured before dialysis.

test (for categorical variables), as appropriate. Associations between patient characteristics [age, gender, glycosylated hemoglobin $\left(\mathrm{HbA}_{1 \mathrm{C}}\right.$ ), serum albumin and urinary albumin excretion (measured by ACR)] and $\mathrm{SCH}$ were assessed using simple and multiple logistic regression analysis. Variables such as age, gender, $\mathrm{HbA}_{1 \mathrm{C}}$, serum albumin, and $\mathrm{ACR}$ were selected to be adjusted in the logistic regression model by virtue of them being confounders in the association between SCH and ESRD or by a process of forward selection of variables where variables that had significant association with $\mathrm{SCH}$ in unadjusted analysis were included in the adjusted model. Variables that were neither confounders nor had a significant association with SCH in the unadjusted model were not included in the adjusted model. Logistic regression analysis, expressed as odds ratio, gave us a measure of the association between selected variables and SCH. Subsequently, multiple linear regression analysis was used to assess the association between $\mathrm{SCH}$ and serum albumin after adjusting for other variables: age, gender, $\mathrm{HbA}_{1 \mathrm{C}}$, and ACR. Here, again, variable selection was similar to what has been described for logistic regression analysis. The multiple linear regression analysis gave us a numerical association between selected variables and $\mathrm{SCH}$. A value of $\mathrm{p}<0.05$ was considered statistically significant. Statistical analysis was performed using SPSS for Windows (version 15.0; SPSS, Chicago, Ill., USA).

\section{Results}

Of the 137 ESRD patients (mean age: $43 \pm 13.38$ years), 107 were males (78.1\%), 45 diabetics (32.8\%; all had type 2 diabetes mellitus and none type 1 diabetes mellitus), 127 hypertensives (92.7\%), and 38 were smokers (27.7\%). Baseline characteristics are listed in table 1. 


\section{CardioRenal Medicine}

\begin{tabular}{|c|c|}
\hline \multicolumn{2}{|l|}{ Cardiorenal Med 2011;1:255-260 } \\
\hline $\begin{array}{l}\text { DOI: 10.1159/000332757 } \\
\text { Published online: October 12, } 2011\end{array}$ & $\begin{array}{l}\text { (c) } 2011 \text { S. Karger AG, Basel } \\
\text { www.karger.com/crm }\end{array}$ \\
\hline
\end{tabular}

Table 2. Association between patient characteristics and $\mathrm{SCH}$

\begin{tabular}{|c|c|c|c|c|c|c|}
\hline \multirow{2}{*}{$\begin{array}{l}\text { Patient } \\
\text { characteristics }\end{array}$} & \multicolumn{2}{|l|}{ Model 1} & \multicolumn{2}{|l|}{ Model 2} & \multicolumn{2}{|l|}{ Model 3} \\
\hline & OR (95\% CI) & $\mathrm{p}$ value & OR (95\% CI) & $\mathrm{p}$ value & $\beta(95 \% \mathrm{CI})$ & $\mathrm{p}$ value \\
\hline Age & $1.11(0.96-1.19)$ & 0.211 & $1.03(0.91-1.16)$ & 0.183 & $0.34(-0.21$ to 0.48$)$ & 0.531 \\
\hline Gender & $0.99(0.89-1.05)$ & 0.174 & $1.03(0.91-1.15)$ & 0.117 & $-0.21(-0.55$ to 0.35$)$ & 0.233 \\
\hline $\mathrm{HbA}_{1 \mathrm{C}}$ & $1.02(0.91-1.14)$ & 0.076 & $1.06(0.82-1.28)$ & 0.423 & $0.36(-0.12$ to 0.78$)$ & 0.078 \\
\hline Serum albumin & $3.37(1.91-5.21)$ & 0.012 & $3.11(2.15-4.98)$ & 0.036 & $-4.61(-2.75$ to -5.92$)$ & 0.026 \\
\hline ACR & $1.14(0.85-1.44)$ & 0.354 & $1.18(0.88-1.47)$ & 0.276 & $0.91(-0.10$ to 1.34$)$ & 0.122 \\
\hline
\end{tabular}

Model 1: unadjusted logistic regression analysis; model 2: multiple logistic regression analysis; model 3: multiple linear regression analysis. $\beta=\beta$ coefficient. The dependent variable in this model is TSH.

SCH prevalence was $24.8 \%$ (34 patients). Mean ACR was $1,573.6 \pm 523.1 \mathrm{mg} / \mathrm{g}$, with no patient having nephrotic-range proteinuria. Patients with $\mathrm{SCH}$ had significantly lower serum albumin levels compared to patients with normal serum TSH levels (table 1). Serum albumin was significantly associated with SCH in both unadjusted (OR: 3.37, 95\% CI: 1.91-5.21, p = 0.012 ) and adjusted (OR: 3.11, 95\% CI: $2.15-4.98, \mathrm{p}=0.036$ ) logistic regression analysis (table 2). All other variables did not have a significant association. Multiple linear regression analysis identified that for every $1 \mathrm{~g} / \mathrm{dl}$ drop in serum albumin TSH increased by $4.61 \mu \mathrm{IU} /$ $\mathrm{ml}(95 \% \mathrm{CI}: 2.75-5.92, \mathrm{p}=0.026)$.

\section{Discussion}

Our study has shown a high prevalence of SCH (24.8\%) in ESRD patients. Our results are concordant with similar studies in other populations linking renal impairment with thyroid disease. In a study by Lim [12], the prevalence of goiter in ESRD was 0-58\% and of SCH 0-9.5\%. In the patients studied by Kaptein et al. [13] in 1988, the prevalence of goiter was as high as $43 \%$ compared to only $6.7 \%$ in the control group. In another report, the prevalence of goiter in ESRD was 58\% [14]. Lo et al. [10] had correlated hypothyroidism with different levels of estimated GFR according to National Kidney Foundation CKD staging and concluded that reduced kidney function was associated with an increase in the prevalence of $\mathrm{SCH}$ and overt hypothyroidism. In agreement with our study, in their study prevalence of hypothyroidism (combining overt hypothyroidism and $\mathrm{SCH}$ ) amounted to $23.1 \%$ in CKD patients with an estimated GFR $<30 \mathrm{ml} / \mathrm{min} / 1.73 \mathrm{~m}^{2}$. Similarly, Chonchol et al. [9] observed an $18 \%$ prevalence of SCH in CKD patients not requiring dialysis. Kang et al. [15] reported that SCH was common among ESRD patients who were receiving continuous ambulatory peritoneal dialysis and that it may be associated with cardiac dysfunction.

In CKD patients, thyroid hormone physiology is known to be altered. Baseline TSH becomes elevated, reaching sometimes levels $>20 \mu \mathrm{IU} / \mathrm{ml}$, response to exogenous thyrotropinreleasing hormone (TRH) gets blunted, diurnal rhythm of TRH gets disturbed, and there is an observed reduction in serum $\mathrm{T}_{4}$ levels [13]. The Wolff-Chaikoff effect or increase in totalbody inorganic iodide can block thyroid hormone production and hence may explain the higher frequency of goiter and hypothyroidism in CKD patients [13]. Further, chronic metabolic acidosis may cause hypothyroidism in these patients. The possible mechanisms were demonstrated by Brungger et al. [16] in their experimental model. They showed that meta- 


\section{CardioRenal Medicine}

bolic acidosis significantly decreased serum $\mathrm{T}_{3}$ and $\mathrm{T}_{4}$ levels, with a corresponding increase in serum TSH levels thereby resulting in hypothyroidism.

Our study has shown a decreased level of serum albumin to be a risk factor for SCH in ESRD patients. Our patients with SCH had significantly lower serum albumin levels compared to patients with normal TSH (table 1). Contrary to our observation, Kang et al. [15] reported that in their study cohort comprising 51 ESRD patients on continuous ambulatory peritoneal dialysis, patients with SCH had significantly higher serum albumin levels compared to patients with normal serum TSH levels. The reason for this difference is not clear. However, the important differences between our study and their study are that they included patients on continuous ambulatory peritoneal dialysis while our study involved hemodialysis patients; further, their study cohort was relatively small compared to ours. Details about urinary albumin loss in their study cohort are not known. These differences render it difficult to arrive at a conclusion.

Gilles et al. [17] made the interesting observation that patients with proteinuria had higher TSH levels, which can be explained by the possible loss of thyroid hormones in the urine. Evidence has not favored the association between hypoalbuminemia and other endocrine abnormalities in CKD [18]. However, hypoalbuminemia in patients with CKD is an independent risk factor for cardiovascular mortality [19]. There have been controversies as to whether SCH in ESRD warrants thyroxine supplementation. Depressed thyroid function can be considered as an adaptation to minimize protein catabolism in ESRD patients. Hence, attempts to correct this might be detrimental to the patient. Proof to this statement comes from the observation that ESRD patients who received thyroxin replacement were observed to have a negative nitrogen balance and an increased leucine flux [20]. However, the cardiovascular risk among patients with a combination of ESRD, SCH, and hypoalbuminemia is yet to be determined. The effect of thyroxine replacement in this subgroup has to be answered by future randomized trials.

\section{Limitations}

The cross-sectional study design prevented us from understanding the temporality in the association between SCH, serum albumin, and ESRD. The small sample size was a second limitation that prevented us from estimating effect modification due to gender, age, and diabetes status. Single measurements of all laboratory values create doubts regarding the precision of these estimates. Also, a search for etiology of SCH or a measure of anti-thyroid antibodies was not performed in our study which limits us from understanding if the SCH observed in our patients was related to decreased GFR or to a primary thyroid pathology.

\section{Conclusions}

In conclusion, our study has shown a $24.8 \%$ prevalence of $\mathrm{SCH}$ among a cohort of ESRD patients. Hence, it may be a good practice to routinely monitor thyroid functions in all ESRD patients. SCH is associated with serum albumin in ESRD patients. Further larger randomized trials and longitudinal follow-up may be needed to answer the controversies regarding thyroxin replacement in ESRD patients with $\mathrm{SCH}$, especially when associated with hypoalbuminemia.

\section{Disclosure Statement}

The authors have no conflict of interest to disclose. 


\section{CardioRenal Medicine}

Cardiorenal Med 2011;1:255-260

DOI: $10.1159 / 000332757$

Published online: October 12, 2011

Shantha et al.: Hypothyroidism and CKD

\section{References}

1 Agarwal SK, Srivastava RK: Chronic kidney disease in India: challenges and solutions. Nephron Clin Pract 2009; 111:c197-c203.

2 Muthu MK: Prevention of chronic renal failure at the community level. Kidney Int Suppl 2003; 83:S86-S89.

- 3 Ryan TP, Fisher SG, Elder JL, Winters PC, Beckett W, Tacci J, Sloand JA: Increased cardiovascular risk associated with reduced kidney function. Am J Nephrol 2009;29:620-625.

4 Villar HC, Saconato H, Valente O, Atallah AN: Thyroid hormone replacement for subclinical hypothyroidism. Cochrane Database Syst Rev 2007;3:CD003419.

-5 Baskin HJ, Cobin RH, Duick DS, Gharib H, Guttler RB, Kaplan MM, Segal RL, American Association of Clinical Endocrinologists: American Association of Clinical Endocrinologists medical guidelines for clinical practice for the evaluation and treatment of hyperthyroidism and hypothyroidism. Endocr Pract 2002;8:457-469.

6 Dillmann WH: Mechanism of action of thyroid hormones. Med Clin North Am 1985;69:849.

7 Serter R, Demirbas B, Korukluoglu B, Culha C, Cakal E, Aral Y: The effect of L-thyroxine replacement therapy on lipid based cardiovascular risk in subclinical hypothyroidism. J Endocrinol Invest 2004;27:897-903.

8 Lim VS, Fang VS, Katz AI, Refetoff S: Thyroid dysfunction in chronic renal failure. A study of the pituitary-thyroid axis and peripheral turnover kinetics of thyroxine and triiodothyronine. J Clin Invest 1977;60:522-534.

-9 Chonchol M, Lippi G, Salvagno G, Zoppini G, Muggeo M, Targher G: Prevalence of subclinical hypothyroidism in patients with chronic kidney disease. Clin J Am Soc Nephrol 2008;5:1296-1300.

10 Lo JC, Chertow GM, Go AS, Hsu CY: Increased prevalence of subclinical and clinical hypothyroidism in persons with chronic kidney disease. Kidney Int 2005;67:1047-1052.

11 Levey AS, Bosch JP, Lewis JB, Greene T, Rogers N, Roth D: A more accurate method to estimate glomerular filtration rate from serum creatinine: a new prediction equation. Modification of Diet in Renal Disease Study Group. Ann Intern Med 1999;130:461-470.

12 Lim VS: Thyroid function in patients with chronic renal failure. Am J Kidney Dis 2001;38(suppl 1):S80-S84.

13 Kaptein EM: Thyroid hormone metabolism and thyroid diseases in chronic renal failure. Endocr Rev 1996;17:45-63.

14 Ramirez G, Jubiz W, Gutch CF, Bloomer HA, Siegler R, Kolff WJ: Thyroid abnormalities in renal failure. A study of 53 patients on chronic hemodialysis. Ann Intern Med 1973;79:500-504.

15 Kang EW, Nam JY, Yoo TH, Shin SK, Kang SW, Han DS, Han SH: Clinical implications of subclinical hypothyroidism in continuous ambulatory peritoneal dialysis patients. Am J Nephrol 2008;28:908-913.

-16 Brungger M, Hulter HN, Krapf R: Effect of chronic metabolic acidosis on thyroid hormone homeostasis in humans. Am J Physiol 1997;272:F648-F653.

17 Gilles R, den Heijer M, Ross AH, Sweep FC, Hermus AR, Wetzels JF: Thyroid function in patients with proteinuria. Neth J Med 2008;66:483-485.

18 Jabbar Z, Aggarwal PK, Chandel N, Kohli HS, Gupta KL, Sakhuja V, Jha V: High prevalence of vitamin D deficiency in north Indian adults is exacerbated in those with chronic kidney disease. Nephrology (Carlton) 2009;14:345-349.

19 Shah NR, Dumler F: Hypoalbuminaemia - a marker of cardiovascular disease in patients with chronic kidney disease stages II-IV. Int J Med Sci 2008;5:366-370.

20 Lim VS, Flanigan MJ, Zavala DC, Freeman RM: Protective adaptation of low serum triiodothyronine in patients with chronic renal failure. Kidney Int 1985;28:541-549. 